\title{
Omuz kuşağı ve humerus diyafiz kırıkları
}

\section{Shoulder girdle and humeral shaft fractures}

\author{
Volkan Kılınçoğlu' ${ }^{1}$, Ahmet Mert ${ }^{2}$ \\ ${ }^{1}$ Gaziantep Üniversitesi Tıp Fakültesi, Ortopedi ve Travmatoloji Anabilim Dalı, Gaziantep \\ ${ }^{2}$ Sağlık Bakanlığı, Muş Bulanık Devlet Hastanesi, Ortopedi ve Travmatoloji Kliniği, Muş
}

\begin{abstract}
Klavikula ve skapula kırıkları sıklıkla çocukluk çağı omuz kuşağı kırıkları olarak değerlendirilir. Klavikula, \%2,6-5 sıkık oranı ile, vücutta en sık kırılan kemiktir. Özellikle doğum sırasında meydana gelen kırıkların \%90'ını klavikula kırı̆̆ı oluşturur. Daha sonraları, çocukluk çağında direkt omuz üzerine düşme sonucu meydana gelir. Çoğunlukla konservatif tedavi ve takip edilir. Skapula kırıkları ise, nadir görülmesine rağmen genellikle yüksek enerjili travmayla ortaya çıkması ve eşlik eden yaralanma sıklığının fazla olması nedeniyle önemlidir. Skapula kırıkları da sıklıkla konservatif tedavi ve takip edilirken cerrahi gereksinim duyulan durumlar da mevcuttur. Proksimal humerus kırıkları da pediatrik kırıklar arasında yaklaşık yılda binde 1,2-4,4 aralığında insidans ve \%5'den daha az sıklıkla nadir görülen kırıklardandır. Sahip olduğu kalın periost, humerusun $\% 80$ oranında proksimal fizisten büyümesi ve ekleme yakın olması, bu bölgenin kırıklarında iyileşme ve remodelizasyon potansiyelini çok yükseltir. Humerus cisim kırıkları erişkinlere nazaran çocukluk çağında daha nadir görülmekle birlikte, bu dönemdeki tüm humerus kırıklarının \%10'unu, tüm kırıkların ise \%2-5,4'ünü oluşturur. Erişkinlerde olduğu gibi, pediatrik humerus cisim kırıkları da radyal sinir arazı ile komplike olabilir. Yenidoğanlarda doğum travmasıyla meydana gelebilirken, daha büyük yaşlarda çoğunlukla basit düşmeler, trafik kazaları ve spor yaralanmaları etiyolojide rol oynar. Çocukluk çağı humerus kırıklarının primer tedavisi konservatif olmakla birlikte; açık kırık, bilateral kırık, onarım gerektiren arter yaralanması veya patolojik kırık gibi durumlarda cerrahi gereksinimi de doğabilmektedir.
\end{abstract}

Anahtar sözcükler: pediatrik humerus diyafız kırı̆ı; klavikula kırı̆̆; skapula kırı̆̆ı; omuz kuşağı kırıkları
Clavicle and scapula fractures are frequently encountered as the childhood shoulder girdle fractures. Clavicle is the most common fractured bone in the body, with a frequency rate of $2.6-5 \%$. Ninety percent of the fractures during delivery are clavicle fractures. In the childhood period, it is encountered mostly due to falling on to the shoulder. The management is usually conservative. Scapula fractures are rare but important, because it usually occurs with a high energy trauma frequently accompanied by an injury in the adjacent tissues. Scapula fractures are usually managed conservatively however there are also cases, which may necessitate surgical treatment. Proximal humerus fractures are also rare pediatric fractures with a given incidence in the range of 1.2-4.4 per 1000 per year and frequency is less than $5 \%$. The thick periosteum, $80 \%$ of the humerus growth from the proximal physeal and the proximity to the joint increases the healing and the remodulation. Humerus shaft fractures are less common in childhood compared to adulthood, nevertheless in that period they constitute $10 \%$ of the humerus fractures and $2-5.4 \%$ all fractures. As it is the case in adults, the humerus shaft fractures in children may be complicated with radial nerve injury. Injuries during delivery may play a role in the etiology in newborns, while toppling down, traffic accidents, and sport injuries are responsible in most of the cases in childhood. The management of humerus fractures in childhood is usually conservative; however, open fractures, bilateral fractures, arterial injury or pathological fractures may necessitate surgical treatment.

Key words: pediatric humerus corpus fracture; clavicle fracture; scapula fracture; shoulder girdle fracture

\section{PEDIATRIK KLAVIKULA KIRIKLARI}

Klavikula, \%2,6-5 sıklıkla vücutta tüm kırıklar içerisinde en sık görülen kırıktır ${ }^{[1]}$; çocuklarda da en sık görülen kırıklar arasındadır. ${ }^{[2]}$ Üst ekstremite ile vücut arasında köprü vazifesi görmesi nedeniyle, üst ekstremiteye uygulanan tüm kuvvetler klavikula üzerinden

vücuda aktarılır. Hem bu mekanizma hem de vücudun anteriorunda cilt altı yerleşimi nedeniyle travmaya direkt maruz kalması, neden bu kadar sıklıkta kırıldığını açıklamaktadır.

Klavikula, akromiyoklavikular eklem ve sternoklavikular eklem aracılığıyla üst ekstremitenin tüm

- Illetişim adresi: Doç. Dr. Volkan Kılınçoğlu, Gaziantep Üniversitesi Tıp Fakültesi, Ortopedi ve Travmatoloji Anabilim Dalı, Osmangazi Mah., Üniversite Bulv., 27310, Şehitkamil, Gaziantep Tel: 0533 - 3643682 e-posta: v.kilincoğlu@hotmail.com

- Geliș tarihi: 2 Subat 2019 Kabul tarihi: 2 Subat 2019 
hareketlerine katılır. Protraksiyon, retraksiyon ile birlikte omuz abduksiyonuna katılabilmek için rotasyon ve elevasyon yapar. ${ }^{[3]}$

Klavikula, intrauterin dönemde ilk ossifiye olmaya başlayan kemiktir ve yaklaşık 5 . haftada ossifikasyonu başlar. Yine, vücutta epifiz plağı en son kapanan kemik klavikuladır. Klavikulanın longitudinal uzamasının \%80'inden sorumlu olan mediyal epifiz plağı 3. dekada kadar açık kalmaktadır. ${ }^{1]}$

Doğum sırasında en sık kırılan kemik klavikuladır. Tüm doğumların \%0,5'inde ve doğum sırasında meydana gelen kırıkların \%90'ında klavikula kırılır. ${ }^{[4]}$

\section{Yaralanma Mekanizması}

Yenidoğanlarda genellikle doğum sırasında omuz takılması, enstrüman kullanımı veya özelleşmiş manevra uygulanması sonucu klavikula kırığı meydana gelebilir. ${ }^{[5]}$ Yenidoğan klavikula kırıkları çoğunlukla ileri maternal yaş, $4 \mathrm{~kg}$ üzeri doğum ağırlığı ve düzensiz takipli gebelik ile yakın ilişkili bulunmuştur. ${ }^{[4]}$ Klinik olarak belirti vermeyen yenidoğan klavikula kırıklarının tanısı zordur ve bazen atlanabilir.

Daha ileri yaş grubu çocuk klavikula kırıklarında en sık görülen mekanizma, direkt travmaya yol açan, omuz üzerine düşmedir. Bunun dışında, açık el üzerine düşme sonucu klavikula üzerine dolaylı yük bindiren yaralanmalarda da klavikula kırığı meydana gelebilir. Genellikle spor yaralanmaları, trafik kazaları, çocuk suistimalleri veya eğlence amaçlı yapılan aktiviteler sırasında meydana gelen kazalar, kırık etiyolojisinde sıklıkla rol oynar.

\section{Belirti ve Bulgular}

Yenidoğanlarda görülen klavikula kırıklarının tanısında anahtar bulgular, psödoparalizi tablosu ${ }^{[6]}$ ve bebeğin ekstremitesini istemli hareket ettirememesidir. Ayrıca, sternokleidomastoid kasın kırık üzerindeki etkisini ortadan kaldırarak, kırık deplasmanı ile birlikte ağrıyı azaltmak amaçlı başını kırık tarafa eğmesi tanısaldır. Yenidoğanda saptanan asimetrik moro refleksi de klavikula kırığı için uyarıcı olmalıdır. Ayırıcı tanıda brakiyal pleksus hasarı, septik hadiseler, humerus diyafiz ve proksimal uç kırıkları akılda tutulmalıdır.

Daha büyük çocuklarda tanı nispeten daha kolaydır. Klavikula kırıklı çocuk, çoğunlukla kırık taraf ekstremitesini sağlam taraf ekstremitesi ile sabit tutmaya çalışır. Kırık taraf omuz diğer tarafa göre daha düşük, içe ve öne dönük; yine, sternokleidomastoid kasının kırık üzerindeki etkisini nötralize etme amaçlı, kafası kırık tarafa ve çenesi karşı tarafa çevirilmiş pozisyonda durur. ${ }^{[7]}$ Travma sahasında ekimoz, ödem, ağrı ve palpasyonla krepitasyon saptanması, tanı açısından değerli bulgulardır.
Klavikula kırıklarında, aşırı ağrı sonucu ortaya çıkan sternokleidomastoid kas spazmına bağlı atlantoaksiyel rotatuvar instabilite meydana gelerek tabloya eşlik edebilmektedir. ${ }^{[8]}$ Yine klavikula kırıklarına brakiyal arter ve/veya brakiyal pleksus yaralanmaları eşlik edebilir. Tüm bu nedenlerden ötürü klavikula kırıklı hastalarda ayrıntılı nörovasküler muayene yapılması şarttır. Özellikle mediyal $1 / 3$ klavikula kırıkları posteriora deplase ise trakea, özefagus veya ana damarlara bası ortaya çıkabilir. ${ }^{[9]}$ Bu bası sonucu çocukta düzensiz periferik nabız, boyun damarlarında şişme, solunum güçlügüu, konuşma gü çlüğü ve yutma güçlüğü saptanabilir.

\section{Tanı ve Sınıflama}

Illk basamak görüntüleme standart anterior-posterior (AP) grafidir. Yenidoğanlarda ise ultrasonografi (US) klavikula kırıkları hakkında değerli bilgi sağlayabilir. ${ }^{[10]}$ AP grafiye ek olarak kırık deplasmanın daha net anlaşılabileceği $20^{\circ}$ sefalik açılı görüntüleme özellikle lateral 1/3 kırıklarda ek olarak istenmelidir. Akromiyoklavikular eklemi ilgilendiren lateral 1/3 kırıklarda deplasman miktarını saptamada, ağırıklı stres grafileri de ek bilgi sağlaması açısından önemlidir. Mediyal $1 / 3$ kırıklarda ise $40^{\circ}$ sefalik açı ile çekilen "Serendipity" grafisi kırık deplasmanı hakkında daha net bilgi vermesi açısından değerlidir. ${ }^{[11]}$ Serendipity grafisinde sağlam taraf klavikula ve her iki taraf sternoklavikular eklem de grafi içine alındığından, karşılaştırma yapılarak daha doğru bir değerlendirme yapılabilir. Tüm klavikula kırıkları için en değerli ve en ayrıntılı değerlendirme sağlayan tanı aracı üç boyutlu bilgisayarlı tomografi (BT) görüntülemedir.

Klavikula kırıklarının sınıflaması sıklıkla kırığın anatomik yerleşimine göre yapılır. Buna göre, Tip 1 korakoklavikular bağ ile sternokleidomastoid kas arasında kalan orta 1/3 klavikula kırıkları; Tip 2 korakoklavikular bağ lateralinde kalan lateral 1/3 klavikula kırıkları; Tip 3 kırıklar ise sternokleidomastoid kas mediyalinde kalan mediyal $1 / 3$ klavikulayı ilgilendiren kırıklardır (Şekil 1). Tip 2, \%69-85; Tip 1, \%10-21; Tip 3, \%3-5 sıklıkla görülür. ${ }^{[12]}$

\section{Tedavi}

Çocukluk çağı klavikula kırıklarının primer tedavisi konservatiftir. Yenidoğan klavikula kırığında bebek huzursuz değilse kendi haline bırakarak veya bebek huzursuz ise çengelli iğne ile elbise kolunu elbise gövde kısmına 2-3 hafta sabitleyerek konservatif takip yapılır. Bebeğin nazikçe tutulup kucaklanması ve kırık sahasında ilerde ortaya çıkacak kallus şişliği hakkında aile ayrıntılı olarak bilgilendirilmelidir. ${ }^{[5]}$ 

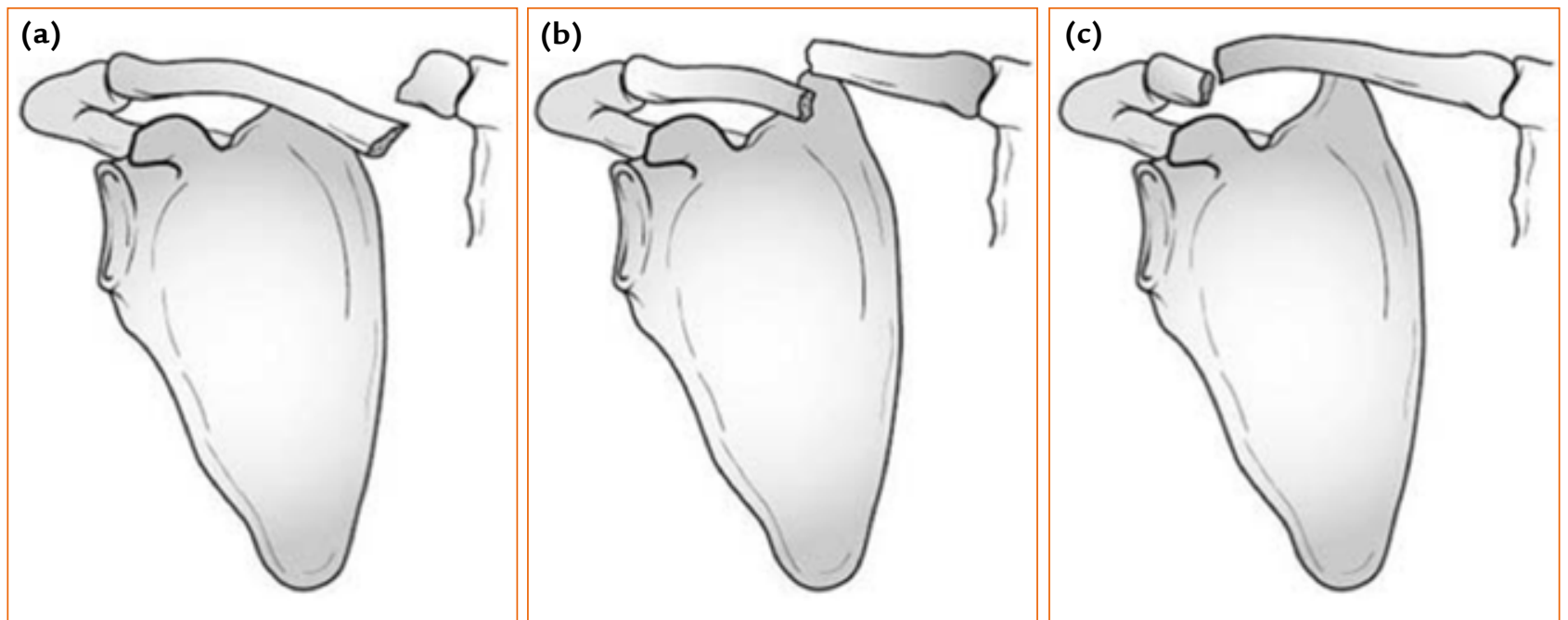

Şekil 1. a, b. Mediyal $1 / 3$ klavikula kırığı (a). Orta $1 / 3$ klavikula kırığı (b). Lateral 1/3 klavikula kırığı (c).

Daha ileri yaş klavikula kırıklarında 1-4 hafta süreyle uygulanacak "sekiz" bandajı veya omuz kol askısı en sık tercih edilen tespit yöntemidir. ${ }^{[13]}$ Sekiz bandajı doğru uygulandığında, her iki omuzu geriye doğru çekerek hem ağrı kontrolü sağlar hem de dizilimi bir miktar düzeltir. Çocuklarda yüksek remodelizasyon kapasitesi nedeniyle, klavikula kırıklarında, redüksiyon gereksinimi olmaksızın konservatif tedaviyle çok başarılı sonuçlar alınabilir.

Cilt bütünlüğünü bozan ve redükte edilemeyen kırıklar, eşlik eden vasküler yaralanma, subklaviyen damar kompresyonu, brakiyal pleksus yaralanması olan ve açık kırıklar cerrahi tedavi adayıdır.

Deplase olmamış veya minimal deplase Tip 1, 2 ve 3 distal klavikula kırıkları için konservatif takip önerilirken, deplase olmuş Tip 4, 5 ve 6 distal klavikula kırıkları için görüş birliği yoktur. Bazı yazarlar, fonksiyonel kayıp oluşturmayacağı için konservatif takibi savunurlarken ${ }^{[14]}$, diğerleri ilerde ortaya çıkabilecek fonksiyonel kayıp ihtimalini düşünerek cerrahi önermektedirler.

Deplase olmamış veya redüksiyonu başarılı deplase mediyal $1 / 3$ kırıklar konservatif takiple başarılı bir şekilde tedavi edilebilir. Özellikle posteriora deplase özofagus, trakea veya ana damar basısı olan mediyal 1/3 kırıklar acil redükte edilmelidir. Gerekirse, ameliyathaneye alınarak genel anestezi altında redüksiyon denenmelidir. Redüksiyon manevrasında, her iki skapula ortasına uzunlamasına yastık konduktan sonra her iki kola longitudinal olarak traksiyon uygulanır. Bu manevra ile başarı elde edilemezse, saha steril olarak boyandıktan sonra, kollara traksiyon uygulanırken çamaşır klempi ile direkt redüksiyon denenir. ${ }^{[15]} \mathrm{Bu}$ şekilde de redüksiyon sağlanamazsa açık redüksiyona geçilmelidir.

\section{PEDIATRIK SKAPULA KIRIKLARI}

Skapulanın kırıkları, güçlü kas yapılarıyla sıkıca korunması nedeniyle nadir görülmektedir. Yine bu nedenle, skapula kırıkları sıklıkla yüksek enerjili yaralanmalar sonucu ortaya çıkar. Yüksek enerjili yaralanma sonucu meydana geldiğinde, kot kırıkları, kafa travması, omuz kuşağı yaralanmaları, pnömotoraks veya hemotoraks tabloya dahil olabilir. ${ }^{[16]}$

\section{Yaralanma Mekanizması}

Skapula kırıklarında, etiyolojide sıklıkla direkt travma meydana getiren trafik kazaları ve yüksekten düşme karşımıza çıkar. Diğer bir mekanizma ise, fleksiyondaki dirsek üzerine düşme sonucu humerus başının glenoide veya akromiyona çarpmasıyla dolaylı yoldan glenoid veya akromiyon kırı̆̆ı da meydana gelmesidir. Ayrıca, glenoid alt kenarına tutunan triseps uzun başı ve korakoide tutunan biseps kısa başının ani kasılmaları sonucu, bu bölgelerde avulsiyon kırıkları meydana gelebilir. ${ }^{[16]}$

\section{Belirti ve Bulgular}

Direkt travmanın etkisiyle posteriorda skapula üzerinde ekimoz, ödem, omuz hareketi ile dorsalde ortaya çıkan ağıı, saptanabilecek bulgulardır. Skapula kırıklarına, hayatı tehdit edici yaralanmalar eşlik 
edebildiğinden, değerlendirme sırasında bu açılardan uyanık olunmalıdır. Ayrıntılı vasküler ve nörolojik muayene yapılması önemlidir. Bu kırıkların \%75'ine eşlik eden ek yaralanmalar mevcuttur. ${ }^{[16]}$ Politravmalı hastalarda, diğer yaralanmalara yoğunlaşıldığında skapula kırıkları gözden kaçabilmekte, atlanabilmektedir.

\section{Tanı ve Sınıflama}

Skapula kırıklarının tanısında ilk yapılması gereken ve standart olan görüntüleme, AP toraks grafisidir. Bu grafiye ek olarak skapula Y grafisi, glenoid kırı̆ğ düşünülen hastalarda aksiller görüntüleme, korakoid kırığı düşünülen hastalara Stryker notch grafisi çektirilerek daha ayrıntılı bilgi elde edilebilir. Kırıkların daha ayrıntılı görüntülenmesi ve değerlendirilebilmesi için en ayrıntılı görüntülemeyi, çektirilecek üç boyutlu BT sağlar.

Skapula kırıklarının sınıflandırmasında kırığın anatomik yerleşimi göz önüne alınır. Buna göre; cisim kırıkları, spina kırıkları, glenoid kırıkları, boyun kırıkları, akromiyon kırıkları ve korakoid kırıkları olarak sınıflandırılabilir. Skapula cisim kırıkları \%35 oranla en sık görülen kırıklardır; bunu \%27 sıklıkla boyun kırıkları ve $\% 7$ sıklıkla korakoid kırıkları takip eder. ${ }^{[17]}$

\section{Tedavi}

Skapula kırıklarının çok büyük kısmı, Velpau bandajı veya omuz kol askısı ile 3-4 hafta tespit edildikten sonra, omuz eklem hareket açıklığını korumaya yönelik egzersizlere başlanarak, konservatif yöntemle tedavi edilir. ${ }^{[16]}$ Eşlik eden aynı taraf klavikula kırığı, deplase korakoid kırı̆ı̆, açık kırık, nörovasküler yaralanma, skapulotorasik ayrışma, omuzda subluksasyon veya instabilite meydana getiren glenoid dudak kırığı ve 5 mm'den daha fazla deplasman gösteren glenoid kavite kırı̆ı varlığında, cerrahi tedavi endikasyonu vardır.

\section{Komplikasyonlar}

Skapula kırıklarında komplikasyon çok sık değildir. Genellikle skapula kırıklarında eşlik eden yaralanmalara bağı komplikasyonlar meydana gelebilir. Geç dönemde; kaynamama, yanlış kaynama, eklemi ilgilendiren kırıklarda artrit, eklem hareket kısıtlılığ, omuz eklem subluksasyonu, tekrarlayan çıkık ve akromiyon malunionlarında impingement olası komplikasyonlardandır.

\section{PEDIATRIK PROKSIMAL HUMERUS KIRIKLARI}

Proksimal humerus kırıkları, pediatrik kırıklar arasında nadir görülen kırıklardandır. Yaklaşık yılda binde 1,2-4,4 aralığında insidansa sahiptir ${ }^{[18]}$ ve tüm pediatrik kırıklar arasında \%5'ten daha az görülür. ${ }^{[19]}$ Proksimal humerus kırıkları, metafizer bölgede veya fiz seviyesinde yerleşim gösterir. Bu bölgenin kalın periosta sahip, fizise yakın ve ekleme yakın olmasına, humerusun da $\% 80$ oranında proksimal fizisten büyümesine bağlı olarak; bu bölgenin kırıklarında iyileşme ve remodelizasyon potansiyeli çok yüksektir.

\section{Yaralanma Mekanizması}

Humerus proksimal kırıkları, nadiren de olsa doğum sırasında meydana gelebilir. Doğum kanalından geçiş sırasında kolun rotasyon ve hiperekstansiyonuna bağlı olarak humerus proksimal fizde ayrılma ortaya çıkabilir. ${ }^{[20]}$ Özellikle iri bebeklerde, zor doğumlarda ve makat gelişlerde, diğer olası kırıklar gibi humerus proksimal kırık riski de daha yüksektir.

Daha ileri yaşlarda, omuz üzerine direkt travma veya açık kol üzerine düşme sonucu indirekt travmalarla humerus proksimal kırı̆ıı meydana gelebilir. Adolesan çăg humerus proksimal kırıklarında, sıklıkla spor yaralanmaları etiyolojide rol oynar. Omuz kuşağı yaralanmalarının neredeyse \%50'sinin spor aktiviteleri sırasında meydana geldiği tahmin edilmektedir. ${ }^{[21]}$

Düşük enerjili travma sonrası meydana gelen humerus proksimal kırıklarında, patolojik kırık mutlaka akılda bulundurulmalıdır. Sıklıkla, unikameral kemik kisti humerus proksimal kısma yerleşim göstererek patolojik kırık etiyolojisinde rol alabilir. ${ }^{[22]}$

\section{Bulgular}

Yenidoğanlarda, bebeğin kırık taraf ekstremiteyi hareket ettirmemesi veya hareketle ağlaması kırık açısından şüphe oluşturur. Ayırıcı tanıda görüntüleme çalışmaları, klavikula kırığı, brakiyal pleksus hasarı, septik hadiseler ve humerus diyafiz kırıkları akılda bulundurularak yapılmalıdır.

Daha büyük çocuklarda, mevcut travma öyküsü ve ağrının daha iyi lokalize edilebilmesi tanıyı kolaylaştırır. Inspeksiyonda diğer tarafa nazaran daha şiş ve dolgun omuz görünümü mevcuttur. Kol abdomene doğru rotasyondadır ve hasta diğer eliyle kolunu sabit tutmaya çalışmaktadır.

\section{Eşlik Eden Yaralanmalar}

Humerus proksimal kırıkları yüksek enerjili travmayla meydana geldiklerinde, tabloya glenohumeral eklem çıkığı da dahil olabilir. ${ }^{[23]}$ Yine, izole kırıklara veya kırıklı çıkıklara brakiyal pleksus hasarı eşlik edebilir. ${ }^{[24]}$ Aksiller bölgeye doğru deplase kırıklarda, damar sinir hasarı meydana gelebilmekle birlikte, bu şekilde ortaya çıkan sinir defisitleri genellikle 6-12 ay içerisinde tamamen geri döner. ${ }^{[25]}$ Ayrıca, yüksek enerjili travma ile meydana gelen humerus proksimal kırıklarına kot kırıkları ve pnömotoraks eşlik edebilir. 


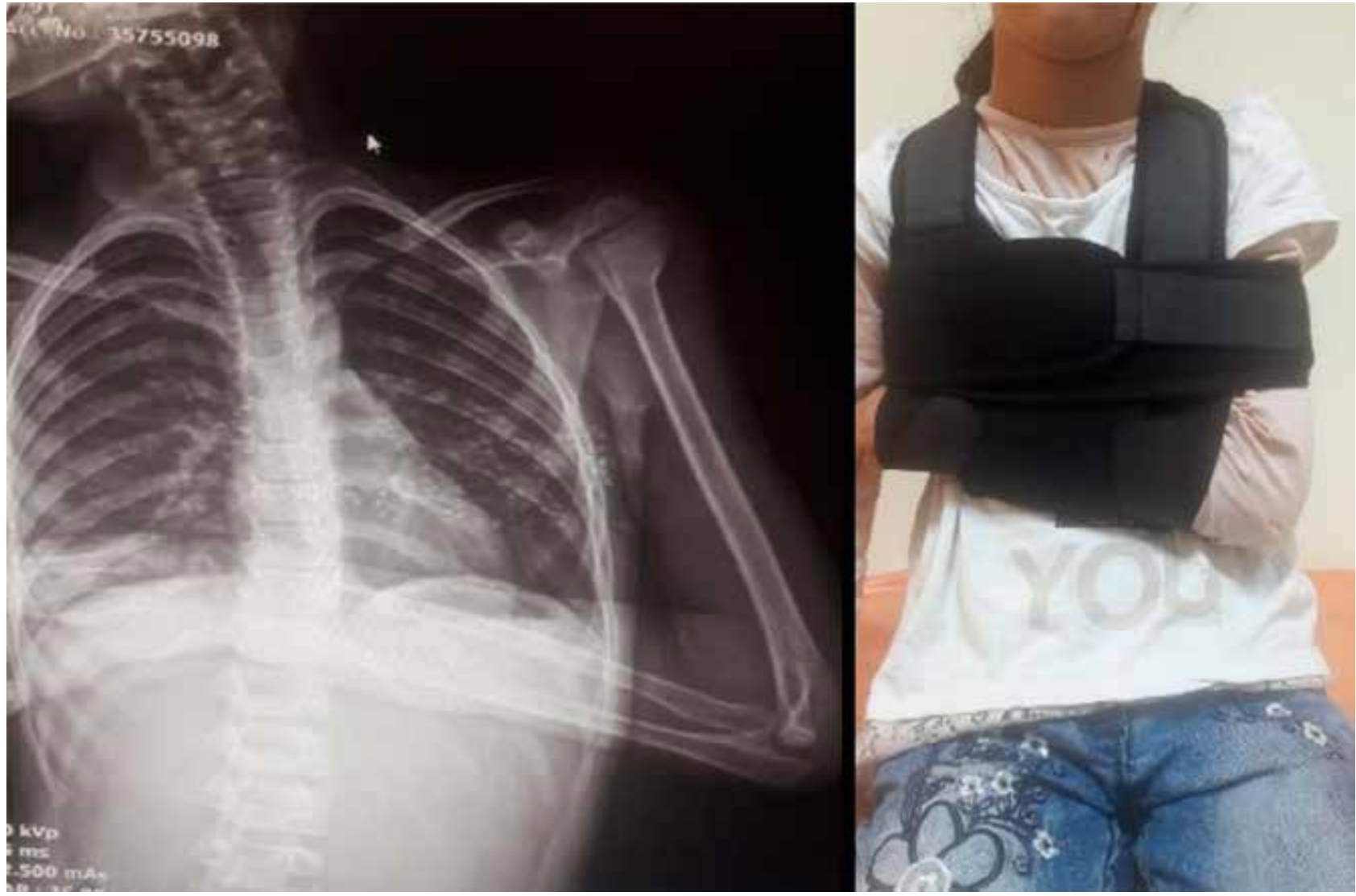

Şekil 2. Humerus proksimal kırıkta Velpau bandajı uygulaması.

\section{Tanı ve Sınıflama}

Humerus proksimal kırık şüpheli omuz travması ile gelen hastada ilk basamak tanı aracı direkt grafidir. Altı aydan küçük çocuklarda humerus proksimal fizisi grafide saptanamayacağından, bu yaş aralığındaki çocuklarda ilk basamak görüntüleme US olmalıdır. Altı aydan büyük çocuklarda direkt grafi ilk basamak görüntüleme aracı olarak istenirken, hastada omuz çıkığı şüphesi varsa birlikte aksiller grafi ve skapular Y grafisi de istenmelidir.

Proksimal fiz kırıklarında epifizer kısım posteriora deplase olursa, istenen direkt grafide epifiz görünmez ve bu duruma 'kaybolan epifiz' bulgusu denir. ${ }^{[26]}$ Humerus proksimal kırıklarında direkt grafi ile yeterli bilgi sağlanamadığında BT yararlı olabilir.

Humerus proksimal metafizer kırıklar, kırığın lokalizasyonuna, deplasmanına ve açlanma durumuna göre sınıflandırılır. Fizisi ilgilendiren kırıklar ise Salter-Harris sınıflamasına göre sınıflanarak değerlendirilir. Bu sınıflamalar dışında, deplasman miktarına göre de Neer sınıflaması tanımlanmıştır. Neer sınıflamasına göre; 5 mm'ye kadar deplasman gösteren kırıklar Evre 1, humerus şaft çapının 1/3'ü kadar deplase kırıklar Evre 2, humerus şaft çapının 2/3'ü kadar deplase kırıklar Evre 3 ve 2/3'ünden daha fazla deplase kırıklar Evre 4 olarak sınıflandırılır.

\section{Tedavi}

Pediatrik humerus proksimal kırıklarının primer tedavisi konservatiftir. Yenidoğanlarda doğum travması sonucu ortaya çıkan humerus proksimal kırıkları için, elbise kolunun çengelli iğne yardımıyla gövdeye tutturulması şeklinde elde edilen tespit ile üç hafta takip yeterlidir. ${ }^{[15]}$ Yenidoğanlarda redüksiyon gerekmeksizin bu şekilde sekelsiz iyileşme elde edilir. Daha büyük yaş grubu çocuklarda Neer Tip 1 ve Neer Tip 2 kırıklar redüksiyon gerekmeksizin konservatif yöntemlerle takip edilir. Bu amaçla, sıklıkla omuz ve kolu tespit eden Velpau bandajı tercih edilir (Şekil 2). Bunun dışında, $U$ ateli ve hanging cast tercih edilebilecek tespit materyalleridir. Dört hafta immobilizasyonu takiben pendulum 
egzersizlerine başlanarak tespit sonlandırılır. On bir yaş altında, kırık deplasman derecesinden bağımsız olarak mükemmel tedavi sonuçları bildirilmiştir. [20]

On bir yaş üzerindeki çocuklarda Neer Tip 3 ve Neer Tip 4 kırıklar redüksiyon gerektirir. ${ }^{[20]} \mathrm{Bu}$ amaçla en sık kullanılan redüksiyon tekniği kol abduksiyon ve fleksiyon pozisyonundayken longitudinal uygulanan traksiyondur. Bu şekilde redüksiyon elde edilemeyen hastalarda, dereceli olarak abduksiyon arttırılarak redüksiyon denemesi devam eder. Kalın periostun, eklem kapsülünün veya biseps tendonunun kırık arasında sıkıştığı bazı durumlarda redüksiyon elde edilemez. ${ }^{[27]}$ Böyle durumlarda, mini bir insizyonla redüksiyonu engelleyen yapı veya yapılar ortadan kaldırılarak redüksiyon elde edilebilir.

Redüksiyonu elde edilemeyen deplase kırıklar, açık kırıklar, kırığa eşlik eden nörovasküler yaralanmalar, multi-travma birlikteliği ve deplase eklem içi kırıklar cerrahi tedavi endikasyonu olan durumlardır.

\section{Komplikasyonlar}

Çocukluk çağı humerus proksimal kırıklarda komplikasyon nadir görülen bir durumdur. Yenidoğanlarda humerus proksimal kırı̆ıına brakiyal pleksus hasarı eşlik edebileceğinden, atlanması olasıdır. Takip muayenelerinde humerus proksimal kırık iyileşmesini takiben bu açıdan tekrar değerlendirme yararlı olacaktır. Pediatrik çağ humerus proksimal kırıklarında varus malunion, olası komplikasyonlar arasında en sık bildirilen komplikasyon olmakla birlikte, fonksiyonel olarak nadiren kısıtlılık meydana getiren bir durumdur.

\section{PEDIATRIK HUMERUS DIYAFIZ KIRIKLARI}

\section{Insidans}

Humerus cisim kırıkları çocuklarda erişkinlere göre daha nadir görülür. Fakat erişkinlerde olduğu gibi radyal sinir arazı ile komplike olabilmektedir. Humerus cisim kırıkları çocuklarda tüm humerus kırıklarının yaklaşık \%10'unu ve tüm kırıkların ise \%2-5,4'ünü oluşturur. ${ }^{[28-30]}$ En sık üç yaş altı ve 12 yaş üstü çocuklarda görülür. ${ }^{[27]}$ Yenidoğanlarda doğum sırasında klavikula kırıklarından sonra en sık görülen kırık humerus cisim kırıklarıdır. ${ }^{[31]}$ Yenidoğanlarda humerus diyafiz kırıklarının görülme insidansı \%0,035-0,34 aralığındadır. ${ }^{[32]}$

\section{Yaralanma Mekanizması}

Yenidoğanlarda makrozomi veya makat geliş gibi zor doğum olması durumunda, doğum manevraları esnasında zorlamaya bağlı, bebeğin kolu başı üzerine kaydığında humerus cisim kırığı ortaya çıkabilmektedir. ${ }^{[32]}$ Daha büyük çocuklarda ise, direkt travmaya yol açacak şekilde açık kol üzerine düşme, araç içi veya dışı trafik kazaları, fırlatma gibi ani kas gücü ortaya çıkaran spor yaralanmaları, döndürme kuvvetinin çok fazla olduğu bilek güreşi gibi spor yaralanmaları, humerus cisim kırığı meydana getirebilir. ${ }^{[33]}$ Özellikle fırlatma ve döndürme hareketi içeren spor yaralanmalarının altta yattığı ve tüm düşük enerjiyle ortaya çıkan kırıklarda, altta yatan kemik patolojisi ihtimali her zaman akılda tutulmalıdır. ${ }^{[22]}$ Özellikle, basit kemik kisti, fibröz displazi, osteogenezis imperfekta, humerus cismine sıklıkla yerleşim göstererek patolojik kırık etiyolojisinde rol oynayabilir. ${ }^{[22]}$ Pediatrik yaş grubu kırıklarının tamamında olduğu gibi, humerus cisim kırıklarında da çocuk istismarı akıldan çıkarılmaması gereken bir konudur. Yapılan çalışmalarda, çocuk istismarına bağlı tüm yeni kırıkların \%61'inin humerus kırıkları olduğu, tüm kırıkların ise \%12'sinde çocuk istismarı varlığı ortaya konmuştur. ${ }^{[34]}$ Çocuk istismarına bağlı humerus kırıkları, genellikle kolun rotasyona zorlanmasıyla, spiral oblik veya direkt humerus üzerine darbe ile, transvers şekilli olabilmektedir.

\section{Değerlendirme ve Tanı}

Yenidoğan bebeklerde bebeğin kolunu hareket ettirememesi veya koluna dokunulduğunda ağlaması humerus cisim kırığından şüphe edilmesi gereken ilk bulgulardır. Böyle bir klinik tabloda ayırıcı tanılar da göz önünde bulundurularak değerlendirmeye başlanmalıdır. Bebeğin doğum şekli, doğum ağırlığı mutlaka sorgulanmalıdır. Sonraki aşamada; diğer ekstremitelerde hareket kaybı varlığı, aynı taraf önkol ve elde hareket olup olmadığı, şişlik, ekimoz, ısı artışı gibi septik belirteç olup olmadığı mutlaka ayrıntılı olarak değerlendirilmelidir. Ayırıı tanılar arasında; klavikula kırığı, septik artrit, hemipleji, humerus fizis kırığı veya brakiyal pleksus hasarı göz önünde bulundurulmalıdır. Özellikle, asimetrik Moro refleksi ve yalancı paralizi varlığı ile humerus cisim kırığı brakiyal pleksus hasarını taklit edebilmektedir. ${ }^{[35]}$

Daha büyük çocuklarda ise tanı nispeten daha kolaydır. Travma sonrası acil servise getirilen çocukta travma almayan eliyle travma alan taraf kolunu gövdenin yanında sabit tutmaya çalışması, tanı açısından uyarıcı olmalıdır. Yine bu çocuklarda, kolda inspeksiyonla saptanan deforme görünüm varlığı sıktır. Yine, kırık alanında palpasyonla aşırı hassasiyet, şişlik ve ekimoz varlığı da ortaya konması gereken tanı parametreleridir. Humerus cisim kırığı ile gelen çocukların fizik muayenesinde, erişkinlerde olduğu gibi ayrıntılı nörolojik ve vasküler muayene şarttır. Erişkinlerde olduğu gibi, çocuk humerus cisim kırıkları da radyal sinir arazı ile komplike olabildiğinden, özellikle radyal sinir muayenesi dikkatlice yapılmalıdır. ${ }^{[6]}$ Radyal sinir hasarı, 1. ve 
2. parmak arasındaki birinci web aralığı dorsalde duyu kaybı, el bileği, parmaklar ve başparmak dorsifleksiyonda kuvvet kaybı ve önkol supinatörlerinde kuvvet kaybı ile karakterizedir. Vasküler yaralanma humerus cisim kırıklarında çok nadir olmasına karşın, fizik muayene esnasında distal nabızlar palpe edilerek ve radyolojik değerlendirmeler yapılarak vasküler hasar olup olmadığı ortaya konulmalıdır.

\section{Sınıflandırma}

Erişkinler için geliştirilmiş humerus cisim kırı̆gı sınıflaması, çocuk humerus kırıklarının değerlendirme ve tedavisinde yararlı değildir. Bunun yerine, pratik kullanımda daha yararlı olan en kullanışlı ve en basit sınıflandırma, kırığın tanımlanmasına dayanan sınıflandırma yöntemidir. Bu yöntemde, kırığın yerleşimi ve kırık konfigürasyonu kullanılır. Buna göre, kırığın yerleşimi üst, orta, alt $1 / 3$ humerus cisim kırığı şeklinde tanımlanır. Kırık konfigürasyonu ise spiral, transvers, oblik, kısa oblik veya spiral oblik şeklinde tanımlanır.

\section{Görüntüleme}

Hastanın ilk geliş değerlendirmesinden elde edilen bilgi ve bulgular eşliğinde, ayırıcı tanılar da akılda tutularak, görüntüleme çalışmalarına geçmek gerekir. ilk basamak görüntüleme direkt grafidir. Bebeklerde ve yaşça küçük çocuklarda tek doz alınan grafide humerus, dirsek, önkol, omuz, klavikula ve akciğer grafisi bir arada değerlendirilebilmektedir. Pediatrik çağ kırıkların tamamında olduğu gibi, bu kırıklarda da ek yaralanmaları atlamamak adına karşılaştırmalı grafi çektirmek yararlı olacaktır. Ayırıcı tanıda patolojik kırık düşünüldüğünde $B T$ ve MR görüntülemeleri yapılmalıdır. Yine, ayırıcı tanıda septik artrit düşünüldüguünde US ve enfeksiyon kan belirteçleri istemek gereklidir. Yenidoğan bebeklerde ayırıcı tanıda brakiyal pleksus hasarı düşünüldügünde elektromiyografi (EMG) istenerek tanı konmalı veya dışlanmalıdır.

\section{Tedavi}

Pediatrik grup humerus cisim kırıklarının tamamında, birincil tedavi yaklaşımı konservatiftir. Yenidoğan humerus cisim kırıkları tedavisinde üç hafta süreyle uygulanan omuz kol askısı veya Velpau bandajı, sıklıkla tercih edilen tedavi yöntemidir. Yenidoğanlarda iyileşme ve remodelizasyon potansiyeli çok yüksek olduğundan, dizilimi düzeltme gerekli değildir. Kırık remodelizasyonunun \%40-50'si, takip eden iki yıl içerisinde gerçekleşir. ${ }^{[37]}$ Takiplerde kırık kallusu belirgin hale geldiğinde elle hissedilebileceğinden ebeveynler bu konuda bilgilendirilmelidir.
Humerusun alt ekstremite uzun kemikleri gibi yük taşıyan kemik olmaması ve omuz eklem hareket genişliğinin fazla olmasından kaynaklı, aksiyel ve rotasyonel sapmalar bu kırıklarda daha fazla tolere edilebilir. Varus-valgus açılanması $20-30^{\circ}$ 'den, AP açılanmalar ise $20^{\circ}$ 'den daha fazla olduğunda klinik olarak görünür hale gelir. ${ }^{[38]}$ Rotasyonel olarak ise $15^{\circ}$ 'ye kadar iç rotasyon deformitesi ve 1,5-2 cm'ye kadar olan kısalık da kabul edilebilir sınırlardır. Kabul edilebilir redüksiyon kriterleri ile ilgili Beaty'nin yayımlamış olduğu kılavuza göre; beş yaş altı çocuklarda toplam $70^{\circ}$ açılanma, 5-12 yaş arasında $40-70^{\circ}$ arası açılanma, 12 yaş üzeri çocuklarda ise $40^{\circ}$ 'ye kadar açılanma ve $\% 50$ temas yüzeyi kabul edilebilir sınırlardır. ${ }^{[27]}$

Pediatrik yaş grubu humerus cisim kırıklarında askı bandajı, $U$ ateli, hanging cast, torakobrakiyal alçı ve koaptasyon atelleri tercih edilebilecek tespit araçlarıdır. Deplasmanın az olduğu kırıklarda, "yaş ağaç" veya torus kırıklarında, askı ve bandaj tespiti başarıyla uygulanan tedavi yöntemidir.

Deplase kırıklarda; kabul edilebilir sınırlara getirilecek şekilde redüksiyon yapıldıktan sonra tespit için kullanılabilecek ve sıklıkla tercih edilen diğer bir yöntem $U$ atelidir (Şekil 3). ${ }^{[38]}$ Omuz üzerinden başlanarak kol lateralinden distale uzatılan atel olekranon altından döndükten sonra aksillaya uzatılarak tespit sağlanır. ${ }^{[39]}$ Özellikle çocuklarda, bu alçı tekniği ile oldukça başarılı sonuçlar elde edilmiştir. ${ }^{[38]}$

Deplasmanın daha fazla olduğu ve dizilimin kontrol edilmesinin zor olduğu kırıklarda ise Velpau bandajı ve torakobrakiyal alçılama tercih edilebilecek tedavi yöntemleridir. ${ }^{[36]}$

Coldwell[ ${ }^{[0]}$ tarafindan tanımlanan hanging cast ise yerçekimi etkisiyle dizilimi sağlama prensibine dayanan bir yöntemdir (Şekil 4). Bu yöntemde, önkol supinasyonda iken yapılan uzun kol sirküler alçı, bir askı yardımıyla boyuna asılır. ${ }^{[39]}$ Bu sayede, alçının ağırlığı kırık hattında longitidunal bir çekme kuvveti ortaya çıkarır. Askının yerinin değiştirilebilmesi sayesinde, varus-valgus ve ön-arka dizilim bozukluklarına müdahale edilebilir. Hanging cast yerçekimi etkisi prensibi ile çalıştığından, omuzda inferior subluksasyon, azalmış dış rotasyon ve omuz eklem sertliği olası komplikasyonları arasındadır.

Erişkin humerus cisim kırıklarında konservatif tedavide sıklıkla tercih edilen Sarmiento breysleri çocuk humerus kırıklarında çok sık tercih edilmemektedir. Çocuklardaki bedensel farklııklar nedeniyle kullanımı pratik değildir. Genellikle $U$ ateli ile 2-3 hafta takip sonrası Sarmiento breysi uygulanarak tedavi devam ettirilebilmektedir. ${ }^{[41]}$ 


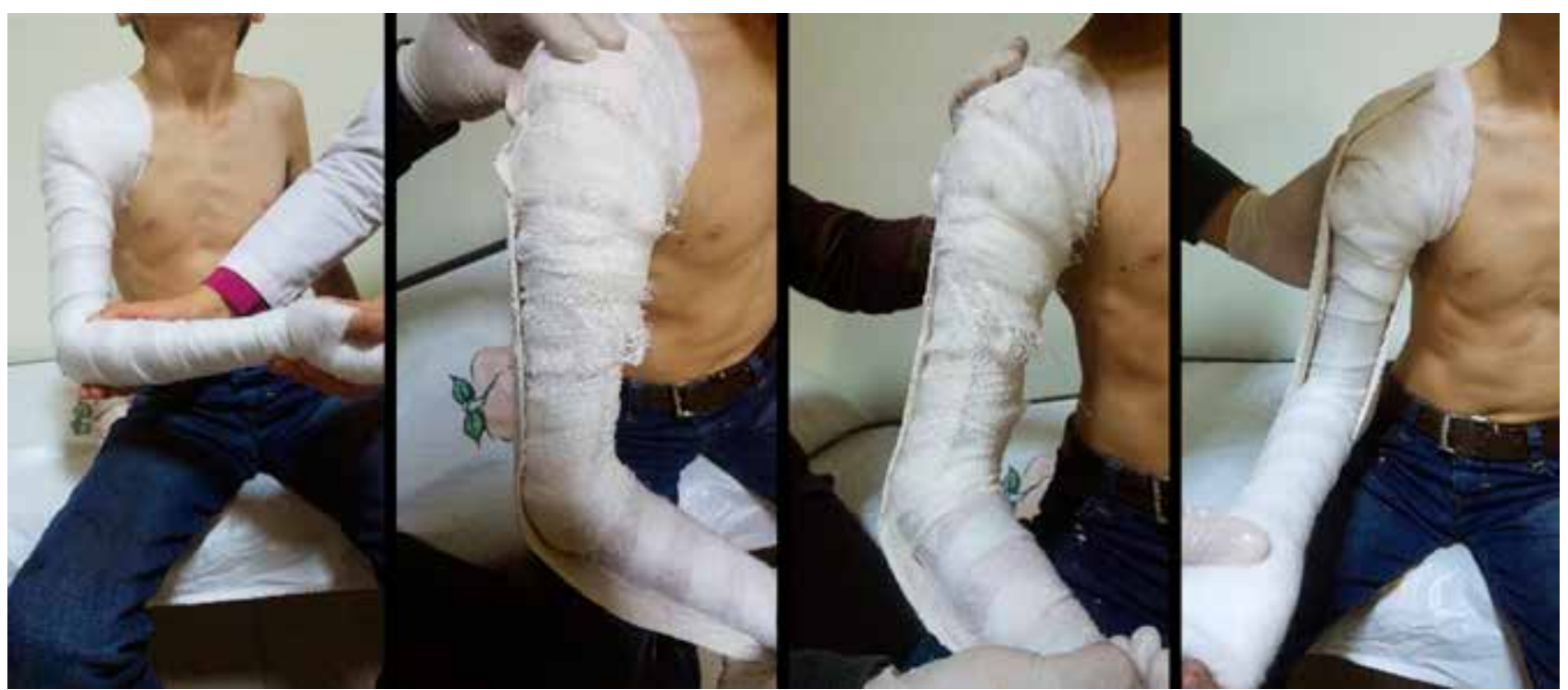

Şekil 3. Humerus cisim kırığında $U$ ateli uygulaması.

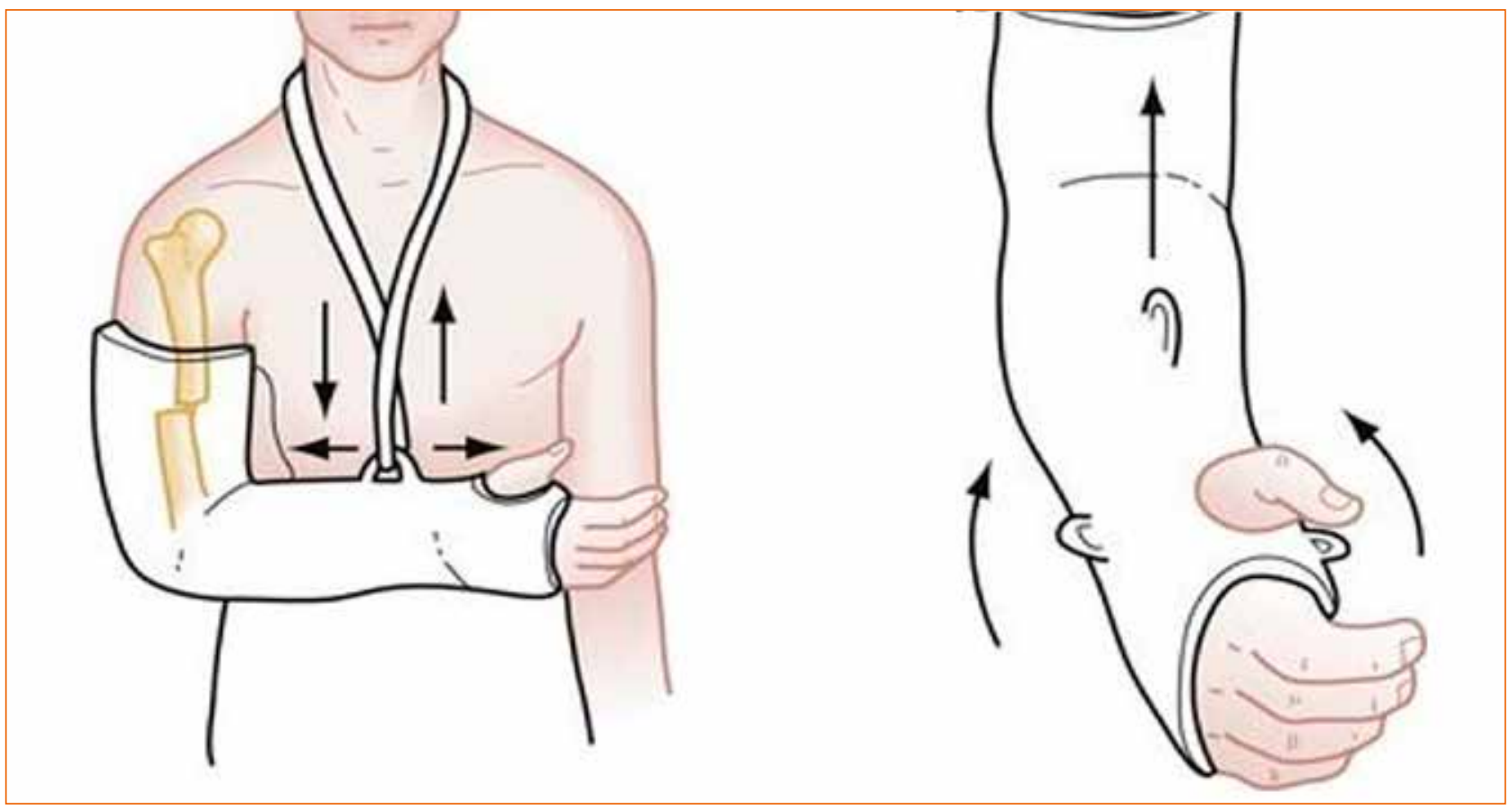

Şekil 4. Humerus kırığında hanging cast uygulaması.

Pediatrik yaş grubu humerus cisim kırıklarında cerrahi tedavi nadiren tercih edilecek tedavi yöntemidir. Açık kırık varlığı, çoklu travma, bilateral kırık, arter yaralanması, kompartman sendromu, patolojik kırık, nörolojik hasar varlığı, başarısız kapalı redüksiyon ve aynı taraf üst ekstremite yaralanması cerrahi tedavi endikasyonlarıdır.
Cerrahi tedavi seçenekleri arasında Kirschner telleri ile açık veya perkütan kapalı telleme, plak-vida tespiti, titanyum elastik çivi ile tespit ve eksternal fiksatör, tercih edilebilecek yöntemlerdir. İskelet matüritesini tamamlamış adolesan yaş grubunda intramedüller çivilemenin de tercih edilebileceği yapılan yayınlarda gösterilmiştir. ${ }^{[42]}$ 


\section{Komplikasyonlar}

Erişkinlerde görülen iki büyük komplikasyon olan nonunion ve radyal sinir yaralanması çocuklarda sık değildir. Radyal sinir paralizileri; kırık sırasında, cerrahi sırasında veya cerrahiden çok sonraları ortaya çıkabilir. [43] Literatürde ulnar sinirin kırık hattında sıkışmasına bağlı ulnar sinir paralizisi de bildirilmiştir. ${ }^{[44]}$

Kol bölgesi fasyasının önkol fasyası kadar güçlü olmamasına bağlı olarak, kompartman sendromu bu bölgede sık görülmez. Olası diğer komplikasyonlardan biri de damar yaralanmasıdır. Damar yaralanması varlığında hızlı tanı ve müdahale şarttır. Cerrahi tedavi uygulanan hastalarda enfeksiyon olası bir diğer komplikasyondur.

Geç dönem komplikasyonlardan olan malunion ve nonunion çocuk humerus kırıklarında nadiren görülebilir. Varus-valgus açılanmasında $20-30^{\circ}$, anteriorposterior açılanmada $20^{\circ}$ ve rotasyonda $15^{\circ} \mathrm{kabul}$ edilebilir sınırlardır.

\section{KAYNAKLAR}

1. Jeray KJ. Acute midshaft clavicular fracture. J Am Acad Orthop Surg 2007;15(4):239-48. Crossref

2. Landin LA. Fracture Patterns in Children: Analysis of 8,682 Fractures with Special Reference to Incidence, Etiology and Secular Changes in a Swedish Urban Population. Acta Orthop Scand 1983:54(sup202);3-109. Crossref

3. Moseley HF. The clavicle its anatomy and function. Clin Orthop Relat Res 1968;58:17-28. Crossref

4. Beall MH, Ross MG. Clavicle fracture in labor: risk factors and associated morbidities. J Perinatol 2001;21(8):513-5. Crossref

5. Cohen AW, Otto SR. Obstetric clavicular fractures. A threeyear analysis. J Reprod Med 1980;25(3):119-22.

6. Dameron TB, Rockwood CA. Fractures and Dislocations of the Shoulder. In: Rockwood CA, Wilkins KE, editors. Fractures in Children. Philadelphia: JB Lippincott; 1984. pp.624-76.

7. Goddard NJ, Stabler J, Albert JS. Atlanto-axial rotatory fixation and fracture of the clavicle. An association and a classification. J Bone Joint Surg Br 1990;72-B(1):72-5. Crossref

8. Bowen RE, Mah JY, Otsuka NY. Midshaft clavicle fractures associated with atlantoaxial rotatory displacement: a report of two cases. J Orthop Trauma 2003;17(6):444-7. Crossref

9. Gardner $\mathrm{MAH}$, Bidstrup BP. Intrathoracic great vessel injury resulting from blunt chest trauma associated with posterior dislocation of the sternoclavicular joint. ANZJ Surg 1983;53(5):427-30. Crossref

10. Heim D, Herkert F, Hess P, Regazzoni P. Can humerus shaft fractures be treated with osteosynthesis? Helv Chir Acta 1992;58(5):673-8.

11. Rockwood CA. Dislocations of the sternoclavicular joint. AAOS Instr Course Lect 1975;24:144-59.

12. Nordqvist A, Petersson $C$. The incidence of fractures of the clavicle. Clin Orthop Relat Res 1994;(300):127-32. Crossref
13. Stanley D, Norris SH. Recovery following fractures of the clavicle treated conservatively. Injury 1988;19(3):162-4. Crossref

14. Black GB, McPherson JAM, Reed MH. Traumatic pseudodislocation of the acromioclavicular joint in children: a fifteen year review. Am J Sports Med 1991;19:644-6. Crossref

15. Sanders JO, Rockwood CA Jr, Curtis RJ. Fractures and dislocations of the humeral shaft and shoulder. In: Rockwood CA Jr, Wilkins KE, Beatty JH, editors. Fractures in Children. Philadelphia: Lippincott-Raven; 1996. pp.905-1019.

16. Ada JR, Miller ME. Scapular fractures. Analysis of 113 cases. Clin Orthop Relat Res 1991;(269):174-80. Crossref

17. Adams F. The Genuine Works of Hippocrates, Vols 1 and 2. New York: William Wood; 1981.

18. Berger PE, Ofstein RA, Jackson DW, Morrison DS, Silvino $\mathrm{N}$, Amador R. MRI demonstration of radiographically occult fractures: what have we been missing? Radiographics 1989;9(3):407-36. Crossref

19. Mizuta T, Benson WM, Foster BK, Morris LL. Statistical analysis of the incidence of physeal injuries. J Pediatr 1987;7(5):518-23. Crossref

20. Dameron TB Jr, Reibel DB. Fractures involving the proximal humeral epiphyseal plate. J Bone Joint Surg Am 1969;51(2):289-97. Crossref

21. Nordqvist A, Petersson CJ. Incidence and causes of shoulder girdle injuries in an urban population. J Shoulder Elbow Surg 1995;4(2):107-12. Crossref

22. Ahn JI, ParkJS. Pathological fractures secondary to unicameral bone cysts. Int Orthop 1994;18(1):20-2. Crossref

23. Cohn BT, Froimson Al. Salter 3 fracture dislocation of glenohumeral joint in a 10-year-old. Orthop Rev 1986;15(6):403-4.

24. Artico M, Salvati M, D'Andrea V, Ramundo EO, Nucci F. Isolated lesion of the axillary nerve: surgical treatment and outcome in 12 cases. Neurosurgery 1991;29(5):697-700. Crossref

25. Jackson ST, Hoffer MM, Parrish N. Brachial-plexus palsy in the newborn. J Bone Joint Surg Am 1988;70(8):1217-20. Crossref

26. Kleinman PK, Akins CM. The "vanishing" epiphysis: sign of Salter Type I fracture of the proximal humerus in infancy. Br J Radiol 1982;55(659):865-7. Crossref

27. Beaty $\mathrm{JH}$. Fractures of the proximal humerus and shaft in children. Instr Course Lect 1992:41:369-72.

28. Cheng JC, Shen WY. Limb fracture pattern in different pediatric age groups: a study of 3,350 children. J Orthop Trauma 1993;7(1):15-22. Crossref

29. Iqbal QM. Long bone fractures among children in Malaysia. Int Surg 1974;59(8):410-5.

30. Webb LX, Green NE, Swiontkowski MF, editors. Skeletal Trauma in Children. Philadelphia: WB Saunders; 1993. pp.257-81.

31. Fisher NA, Newman B, Lloyd J, Mimouni F. Ultrasonographic evaluation of birth injury to the shoulder. J Perinatol 1995;15(5):398-400.

32. Madsen ET. Fractures of the extremities in the newborn. Acta Obstet Gynecol Scand 1955;34(1):41-74. Crossref

33. Allen ME. Stress fracture of the humerus: a case study. Am J Sports Med 1984;12(3):244-5. Crossref

34. Loder RT, Bookout C. Fracture patterns in battered children. J Orthop Trauma 1991;5(4):428-33. Crossref 
35. Howard NJ, Eloesser L. Treatment of fractures of the upper end of the humerus: an experimental and clinical study. J Bone Joint Surg 1934;16:1-29.

36. Böhler L. Conservative treatment of fresh closed fractures of the shaft of the humerus. J Trauma 1965;5(4):464-8. Crossref

37. Bianco AJ, Schlein AP, Kruse RL, Johnson EW Jr. Birth fractures. Minn Med 1972;55(5):471-4.

38. Dameron TB, Grubb SA. Humeral shaft fractures in adults. Southern Med J 1981;71(12):1461-7. Crossref

39. Fırat A, Şahin A, Çepni Ş. Çocuk alçısı, askılı alçı, humerus cisim kırıklarında alçılama teknikleri. TOTBID Derg 2018;17:281-9. Crossref
40. Caldwell JA. Treatment of fractures in the Cincinnati General Hospital. Ann Surg 1933;97(2):161-76. Crossref

41. Zagorski JB, Latta LL, Zych GA, Finnieston AR. Diaphyseal fractures of the humerus. Treatment with prefabricated braces. J Bone Joint Surg Am 1988;70(4):607-10. Crossref

42. Crolla R, De Vries LS, Clevers GJ. Locked intramedullary nailing of humeral fractures. Injury 1993;24(6):403-6. Crossref

43. Friedman RJ, Smith RJ. Radial nerve laceration 26 years after screw fixation of a humeral fracture -a case report. J Bone Joint Surg 1984;66(6):959-60. Crossref

44. Kane E, EB Kaplan, M Spinner. Observations of the course of the ulnar nerve in the arm. Ann Chir 1973;27(5):487-96. 